\title{
Developing Speaking and Writing Skills of L1 Arabic EFL Learners through Teaching of IPA Phonetic Codes
}

\author{
Hussam Rajab \\ English Language Centre, Dammam Community College (King Fahd University of Petroleum \& Minerals), Dhahran, \\ Saudi Arabia
}

\begin{abstract}
This exploratory study investigated the development of speaking and writing skills of L1 Arabic EFL learners based on their level of perception and understanding of phonetic transcriptions through visualisation of letter-to-symbol representations using the International Phonetic Alphabet (henceforth IPA). The participants were 169 University-level Preparatory Year Program (PYP) male Saudi EFL students. The study was carried out as a pedagogical approach to improve university first year students' pronunciation, correct speech and writing skills. The students selected attended 6, 50-minute Integrated Pronunciation Teaching (IPT) lessons which included IPA transcription codes using both audio and visual teaching methods in addition to one ICT aided lesson. Throughout those lessons, students were initially introduced to the IPA phonetic codes in gradual increase of difficulty and were encouraged to use the monolingual (English-English), Longman Dictionary of Contemporary English (LDCE). Two written tests and one oral test were conducted using a number of carefully selected IPA transcription codes related questions and results were analysed and interpreted. Results obtained showed slight variations between higher and lower ability students in understanding the IPA transcription codes. As a whole, however, the results indicated that students reached a high level of understanding of letter-to-symbol representations - the IPA system - and oral test results proved that phonological awareness can help Saudi students at tertiary level education improve their writing and speaking skills. Above all, learning the phonetic transcription codes helped them develop a sense of autonomy and competence when using monolingual dictionaries. The study concluded with a brief discussion of the ramifications of the study and the potential for further research.
\end{abstract}

Index Terms-EFL, K.F.U.P.M, IPA, IPT, phonemes, phonetic transcription, phonological awareness

\section{INTRODUCTION}

As English language continues to grow and spread as a global lingua franca and as the main language for international communication, EFL teachers need to become more aware of ways to develop the EFL learner's competence by focusing on more effective and successful pedagogical strategies. Achieving effective communication as well as the production of intelligible English pronunciation can be complex for Arabic speakers EFL learners (Rababah, 2005).

One of the important issues the Ministry of Higher Education in Saudi Arabia is addressing nationally and eager to elevate is the overall proficiency level of English among secondary and tertiary level students. Government tertiary level institutions in Saudi Arabia (e.g. Universities and Colleges) are adopting English as a medium of instruction and each follow specially tailored EFL (English as a Foreign Language) courses to meet the needs of their students. However, students leaving high school to join Universities or Colleges in Saudi Arabia face great difficulties trying to catch up with these courses due to the existence of problems in EFL learning. These problems - which mainly exist in mainstream government secondary schools - include inadequacy of target language input, the pervasiveness of the traditional teacher-centred English teaching method, and a considerable use of focus on forms in exercises such as grammar translations and pattern drills in class which renders the learning of English as similar to rote memorization of English vocabulary and sentence structures to students. Very often, students are forced to memorize things they either do not comprehend or have no desire to learn. Thus, English Language Centres at various Saudi Universities follow a structured, intensive EFL program for their PYP students where the emphasis on pronunciation and phonological awareness forms the backbone of the two major disciplines of speaking and writing. This study investigated pronunciation training following the teaching of the IPA codes and how it improved the speaking skills and confidence in Saudi University EFL learners.

\section{LITERATURE REVIEW}

Phonetics is defined broadly as the study of speech sounds (Denes \& Pinson, 1993) using special signs, often different from ordinary letters, to represent the sounds of speech (LDCE, 2005)pp. 1230). Phonological awareness is considered to be the most extensively studied aspect of phonological skills as part of the phonological structure of 
language. Phonological awareness is defined as the ability to manipulate the individual sounds of words independent of their meaning (Foorman, 1991);(Blachman, 1994). (Stanovich, 1993), however, defines "phonological awareness" as the ability to deal explicitly and segmentally with sound units smaller than the syllable.

Despite the fact that research carried out in the USA and UK into how children learn to read and write, as well as on what the best pedagogical methods might be, review articles of earlier significant research in adult ESL/EFL instruction in reading and writing (Grabe, 1991); (PéryWoodley, 1991); (Raimes, 1991) do not mention phonics and/or spelling in the acquisition of English pronunciation. The importance of teaching pronunciation and phonetics cannot be overemphasized. (Stevens, 1991), suggests that all aspects of second language teaching involve the teaching of pronunciation. (Koren, 1995) states that good pronunciations are part and parcel of successful communication. As EFL teaching has moved to language functions and communicative competencies, a new urgency for the teaching of pronunciation has arisen (Celce-Murcia, 1991); (Morley, 1994) ; (Liu, 2011). In addition, pronunciation, generally, plays an important role in helping the learner become an intelligible speaker (Morley, 1998). The research carried out by (Stanovich, 1993) indicates that phonological awareness is the best predictor of the ease of early reading acquisition and in addition, it is a foundational ability underlying the learning of spelling-sound correspondences. Phonological awareness is also an important and essential element for reading progress (Griffith, 1992). A research conducted by (Ingvar Lundberg, Jbrgen Frost, \& Petersen, 1988) also indicates that students with increased phonemic awareness facilitated their subsequent reading acquisition. Phonemes are defined as distinctive feature bundles. That is, a phoneme is the smallest unit that will distinguish between words, e.g., [tEnt] versus [dEnt] (LDCE, 2005) .Two important findings by (Kruidenier, 2002) suggests that phonemic awareness and/or word analysis instruction may lead to increased achievement in other aspects of reading for beginning level adult readers. The second finding suggests that adult non-readers have virtually no phonemic awareness ability and are unable to consistently perform, on their own, nearly all phonemic awareness tasks. Amongst the most difficult learning problems experienced by EFL learners may well be the phonemic differences and variation between languages (James Flege \& Port, 1981). As English spelling is morphophonemic (Stubbs, 1980; Venzky, 1970), understanding how phonemes are represented by single letters as well as spelling patterns can assist in the development of basic ESL literacy (Jones, 1996). This is in line with theories that consider noticing as an interface in language acquisition. According to Schmidt (1995, p. 20), "the noticing hypothesis states that what learners notice in input is what becomes intake for learning". He also considers noticing as a necessary condition for L2 acquisition. One way for the ESL/EFL learners to "notice" L2 English is to learn phonetic transcriptions. Phonetic transcription is merely a written record of the sounds of spoken language. It is the link between acoustics and text. By reading the written symbols, the sequences of speech sounds produced by the original speaker can be reproduced. It helps a speaker of any L1 language to learn the correct pronunciation of another language's words. Using phonetic transcription in the EFL classroom can be very advantageous. It can help the student visualise difficult codes representing words as sounds and therefore increase the EFL student's awareness of English Language second language sound features. It can also help EFL students acquire some autonomy when looking up words and their corresponding pronunciation in the dictionaries. (Atkielski, 2005) mentioned in his paper that written English is only a representation of the spoken language, however, phonetic transcription, in contrast, is an exact representation, without any ambiguity, redundancy, or omission. He concluded his paper with the finding that IPA to the experienced ESL teacher is very easy to teach and its use can save time and facilitate the teaching of concepts related to the spoken language. (Pennington, 1996) believes that the materialisations of sounds through graphic representations (phonetic codes) are useful resources in helping enhance L2 learner pronunciation production quality. Although, phonetic transcription (or phonetic notation) is very convenient in the teaching of a foreign language, it can have the effect of a double-edged sword. If the teaching of phonetic transcription is carried out favourably, it may increase the student's motivation to learn and use phonetic notations. On the other hand, if the teaching is carried out unfavourably, students may perceive the notations as a useless and irrelevant part of their learning of English language. It is therefore important to decide when and how to teach phonetic transcriptions to ESL students. One of the recommended strategies is to have an Integrated Pronunciation Teaching (IPT). IPT has several advantages over non-IPT. The main advantage of IPT is that it does not treat pronunciation as a separate phenomenon from the process of communication - (Kenworthy, 1987) ; (McMullan, 1988).

The IPA system of teaching phonetic transcription was employed in this study due to several factors. The IPA system is the most widely used alphabet for phonetic transcription (Handbook of the International Phonetic Association 1999). Many of the IPA letters are the same as those of the English alphabet. The students at K.F.U.P.M are provided each with a free copy of LDCE (the 2005 edition at the time of this research study) which uses the IPA system (alphabet) of transcription. In addition, the IPA has another advantage when used to teach transcription. The IPA provides transcription of the intonation of speech such as change in pitch, loudness and so on.

\section{METHOD}

The 169 students selected to take part in this study came from 7 different classes (for simplicity, these classes will be assigned group names as follows: Group A, Group B, Group C, Group D, Group E, Group F and Group G). 
TABLE 1.

NUMBER OF STUDENTS IN EACH GROUP.

\begin{tabular}{|l|l|l|l|l|l|l|}
\hline Group & A & B & C & D & E & F \\
\hline Number of Students & 27 & 26 & 24 & 25 & 16 & G \\
\hline
\end{tabular}

The following table illustrates the dates when the study was carried out:

TABLE 2.

DATES FOR DATA COLLECTION.

\begin{tabular}{|c|c|c|c|c|c|c|c|}
\hline Group & A & B & C & D & E & F & G \\
\hline Date & September -October 2005 & February - March 2006 & June - July 2006 & September -October 2007 \\
\hline
\end{tabular}

All of the students were Saudi (with the exemption of 3 Yeminis, 2 Indians, 1 Pakistani and 1 Syrian), males and ranging in age between 18-22 years old. Groups A, B, C, D, F and G were registered with Dammam Community College (DCC) as full time PYP students whereas group E students were registered for the intensive EFL summer course held at K.F.U.P.M. The participants were mixed abilities EFL learners.

At the beginning of the academic year, each student was provided with a free copy of (LDCE, 2005) -, four textbooks from the Skills in English (2005) series (Terry \& Anna Phillips): reading (with supplementary reading resource book), writing, speaking and listening textbooks and in addition, students were given a simplified, custom designed (using word processing) IPA table sheet containing carefully chosen codes. The table included the IPA 21 vowels codes as well as 24 consonants codes. However, in this research study, the focus was on ten consonant codes: /d / , / $/ /, / \mathrm{g} /, / \mathrm{z} /$, /s/ , /p/ , /b/ , /k/ , /g/, /ḑ/, four long and short vowel codes: /i:/ , /I/ , /a:/ , /æ/ and two diphthongs codes /av/ and /ai/ with several examples given for each of these codes. Each student was given a short question (that was related to phonetic transcription) with - a piece of A5 paper size sheet to answer. This was done at the start of this study in order to determine any prior knowledge of the IPA codes or the academic usage of monolingual (English-English) dictionaries. The students were taught these codes in 6, 50- minutes IPT lessons over the period of 6 weeks. They were presented with two IPA codes at a time using the interactive smart board. The codes were briefly explained and pronounced individually to the students and they were requested to familiarise themselves with these codes that represent actual pronunciation of corresponding words. Ample time was given to the students with several examples relating to these codes in order for the students to successfully understand the IPA codes. Questions were asked at the end of each session to retrieve feedback from the students and any difficulties encountered were quickly resolved. The IPA codes presented were placed between forward slashes similar to those indicating phonetic spellings in the LDCE used by the students (LDCE, 2005) and by the Terry \& Anna Philips (2005) Listening and Speaking student's books. At the end of weeks 3 and 6, students were given written tests (Tests 1 and 2) which incorporated four types of questioning: multiple choices, fill in the blank, place words under their consonant/vowel code corresponding column and answer the questions by writing in transcription or vice versa. At the end of week 6 , students were also given an oral test where they were asked two questions relating to the phonetic codes taught and asked to answer them. Those tests were given in order to examine the successful recognition of the selected IPA codes taught in this research study.

The first test was constructed so that it related to 10 of the IPA codes taught to the students in the first three weeks. The second test however, included one section with four additional codes which were not taught to the students - but were included in the IPA codes table- and was included to test the high abilities students. The first test included 16 questions and the second test included 32 questions. The oral/speaking test on the other hand, was straight forward faceto-face interview style which aimed at evaluating the understanding of the IPA codes taught throughout the course as well as the correct pronunciation of words based on the knowledge acquired of these codes in their speaking. The first part of the oral/speaking test included questions related to identifying code(s) representing a specific consonant or vowel sound in a given word pointed at from the interactive smart board. Whereas, the second part included questions related to pronouncing a chosen word (also pointed at from the interactive smart board) correctly.

Tests 1 and 2 were marked manually and scores were entered into a custom made constructed tally table for each code. Pre-marked test papers were photocopied and two other faculty members were asked to mark them to add extra validity to the results. The oral/speaking test was conducted with three instructors. The first instructor interviewed the students individually and the other two instructors recorded marks relating to the IPA codes taught in the research study, separately. Overall group grades and correct/incorrect results for individual IPA codes were analysed using Microsoft Excel® software.

\section{RESULTS}

The first set of results obtained regarding prior knowledge or usage of monolingual (English-English) dictionaries is as follows: 
TABLE 3.

STUDENTS WITH/WITHOUT PRIOR KNOWLEDGE OF PHONETIC TRANSCRIPTION AND/OR USAGE OF MONOLINGUAL (ENGLISH-ENGLISH) DICTIONARIES.

\begin{tabular}{|l|l|l|}
\hline Question & YES & NO \\
\hline Previous Usage of Monolingual (English-English) dictionaries & 10 & 159 \\
\hline Recognising Phonetic Transcriptions & 2 & 167 \\
\hline
\end{tabular}

For each test, the overall group results were presented in a table and are given below (as a percentage \%).

TEST 1

THE RESULTS (GIVEN AS A PERCENTAGE) OF SUCCESSFUL RECOGNITION OF THESE CODES ARE AS FOLLOWS:

\begin{tabular}{|c|c|c|c|c|c|c|c|}
\hline Group & $\mathrm{A}$ & $\mathrm{B}$ & $\mathrm{C}$ & $\mathrm{D}$ & $\mathrm{E}$ & $\mathrm{F}$ & $\mathrm{G}$ \\
\hline Result (\%) & 66 & 63 & 69 & 70 & 90 & 81 & 75 \\
\hline
\end{tabular}

TABLE 4.

TEST 1 INDIVIDUAL GROUPS' RESULTS.

\begin{tabular}{|l|l|l|l|l|l|l|l|l|}
\hline$/ \mathrm{d} /$ & $/ \mathrm{J} /$ & $/ \mathrm{t} /$ & $/ \mathrm{z} /$ & $/ \mathrm{s} /$ & $/ \mathrm{p} /$ & $/ \mathrm{b} /$ & $/ \mathrm{k} /$ & $/ \mathrm{g} /$ \\
\hline 95 & 76 & 67 & 99 & 98 & 54 & 53 & 98 & 69 \\
\hline
\end{tabular}

TABLE 5.

ALL GROUPS' RESUlTS FOR THE 10 SELECTED INDIVIDUAL IPA CODES TAUGHT IN THE FIRST THREE WEEKS (TEST 1). TEST 2 THE RESULTS OF SUCCESSFUL RECOGNITION ARE AS FOLLOWS:

\begin{tabular}{|l|l|l|l|l|l|l|l|}
\hline Group & A & B & C & D & E & F & G \\
\hline Result $(\%)$ & 70 & 65 & 64 & 71 & 92 & 80 & 76 \\
\hline
\end{tabular}

TABLE 6.

TEST 2 INDIVIDUAL GROUPS' RESULTS

\begin{tabular}{|l|l|l|l|l|l|l|l|l|l|l|l|l|l|l|l|l|l}
\hline$/ \mathrm{d} /$ & $/ \mathrm{j} /$ & $/ \mathrm{t} /$ & $/ \mathrm{z} /$ & $/ \mathrm{s} /$ & $/ \mathrm{p} /$ & $/ \mathrm{b} /$ & $/ \mathrm{k} /$ & $/ \mathrm{g} /$ & $/ \mathrm{d} /$ & $/ \mathrm{i} / /$ & $/ \mathrm{I} /$ & $/ \alpha: /$ & $/ \mathrm{a} /$ & $/ \mathrm{aI} /$ & $/ \mathrm{a} /$ \\
\hline 90 & 77 & 66 & 95 & 98 & 50 & 56 & 97 & 73 & 77 & 65 & 69 & 70 & 68 & 79 & 92 \\
\hline
\end{tabular}

TABLE 7.

ALL GROUPS' AVERAGE FOR THE 16 SELECTED INDIVIDUAL IPA CODES TAUGHT IN THE WHOLE OF THE SIX WEEKS OF THE COURSE OF THE RESEARCH STUDY (TEST 2).

\begin{tabular}{|l|l|l|l|l|l|l|l|}
\hline Group & A & B & C & D & E & F & G \\
\hline Result (\%) & 77 & 50 & 61 & 66 & 96 & 85 & 74 \\
\hline
\end{tabular}

TABLE 6.

TEST 2 INDIVIDUAL GROUPS' RESULTS FOR THE ADDITIONAL FOUR IPA SELECTED CODES WHICH WERE NOT TAUGHT IN THE STUDY.

\begin{tabular}{|l|l|l|l|}
\hline$/ \theta /$ & $/ ð /$ & $/ \mathrm{n} /$ & $/ \mathrm{f} /$ \\
\hline 70 & 68 & 79 & 96 \\
\hline
\end{tabular}

Table 7.All groups' average for the 16 selected individual IPA codes taught in the whole of the six weeks of the course of the research study (Test 2).

TABLE 9.

GROUPS' RESULTS FOR THE ORAL TEST.

Oral Test The results of successful recognition are as follows:

\begin{tabular}{|c|c|c|c|c|c|c|c|}
\hline Group & A & B & C & D & E & F & G \\
\hline Result (\%) & 66 & 63 & 69 & 70 & 90 & 81 & 75 \\
\hline
\end{tabular}

TABLE 10.

GROUPS' RESULTS FOR THE 16 SELECTED INDIVIDUAL IPA CODES FOR THE ORAL TEST.

\begin{tabular}{|c|c|c|c|c|c|c|c|c|c|c|c|c|c|c|c|}
\hline$/ \mathrm{d} /$ & $/ \mathrm{d} /$ & $/ \mathrm{t} \mathrm{j} /$ & $|\mathrm{z}|$ & $/ \mathrm{s} /$ & $/ \mathrm{p} /$ & $/ \mathrm{b} /$ & $/ \mathrm{k} /$ & $/ \mathrm{g} /$ & $/ d_{3} /$ & /i:/ & $/ \mathrm{I} /$ & /a:/ & $/ æ /$ & /aI/ & $/ \alpha v /$ \\
\hline 69 & 65 & 60 & 94 & 97 & 49 & 52 & 96 & 70 & 76 & 55 & 64 & 66 & 62 & 72 & 87 \\
\hline
\end{tabular}

\section{CONCLUSION}

It is clear from the data collected that Saudi students did not have great difficulties learning the selected IPA codes and the concept of phonetic transcriptions. This is apparent from the results of the tests that were carried out. The students managed to get most of the consonant codes above and well above 50\% except for $/ \mathrm{p} / \mathrm{and} / \mathrm{b} /$. This is due to the fact that the consonant letters' sounds such as $/ \mathrm{z} /, / \mathrm{s} /, / \mathrm{d} / \mathrm{l} / \mathrm{d} /$ and $/ \mathrm{k} /$ exist in the Arabic language alphabet and are pronounced in the same way in the Arabic language (Swan \& Smith, 2001). Thus, the majority of the students did not have great difficulties identifying these codes or pronouncing words containing these consonants correctly. Although the /g / letter's sound does not exist in the Arabic alphabet, it apparently does not resemble (to L1 Arabic speakers) any other letter's sound and therefore the students managed to recognise and pronounce it correctly. Another reason for this is that the students were taught some rules regarding the differences between / d / / letter's sound and /g/ (e.g. words starting with letter "g" and followed by the vowel "o" have the IPA phonetic symbol /g/ ). The greatest difficulty the students faced was the alternations of letters "P" and "B". Nearly $50 \%$ of the students were not able to distinguish between these two letters in writing, pronouncing (words having ' $\mathrm{P}$ ' or ' $\mathrm{B}$ ' in them) and even in transcribing them. 
Again that may well be traced back to the fact that Arabic language lacks the sound /p/ - (Ibrahim, 1978) and therefore approximated to the nearest Arabic letter ' $\mathrm{B}$ ' which is allophonic to " $\mathrm{P}$ ".

Prior to this study, the students who participated in this study (with the exception of ten students), had little to no knowledge of phonetic transcription and its usage in the monolingual (English-English) dictionaries. Even when the students were each given a copy of the (LDCE, 2005) and were instructed to interpret (or try to explain the purpose of) the IPA codes that followed the words in the dictionary. No acceptable answer or explanation was given. When they were informed that they will learn some of these IPA codes soon, some of them were doubtful of the usefulness or benefits of learning the IPA codes. The very same sceptical students were quick to change their stance and realise the benefits of learning phonetic transcription. They became familiar with the concept of phonetic transcriptions. They understood what these IPA characters and codes stand for and why they are printed in monolingual (English-English) dictionaries. The students realised that passive acquaintance with phonetic transcription helps in enabling them to extract precise and explicit information on pronunciation from dictionaries.

\section{RECOMMENDATIONS FOR FURTHER RESEARCH}

This unprecedented research study could be the starting point of further studies and research in the field of phonetics relating to the Arab EFL learners. The following recommendations for additional studies and research are offered:

1. Replicate the study with a larger number of students (possibly double or triple the number in this study) either at a tertiary institute in Saudi Arabia or any tertiary institute in the region.

2. Replicate the study with EFL learners with L1 other than Arabic (e.g. Chinese EFL learner, Korean EFL learners and so on) and compare the results with this research study.

3. Replicate the study with the rest of the IPA codes and compare the results with this study.

4. Conduct a similar study (preferably considering 1 and 2 earlier) and include statistical analysis using Hypothesis testing (e.g. Null Hypothesis).

\section{APPENDIX A PRONUNCIATION TABLE}

\begin{tabular}{|c|c|c|c|}
\hline \multicolumn{2}{|l|}{ Vowels Codes } & \multicolumn{2}{|c|}{ Consonants Codes } \\
\hline Symbol & Keyword & Symbol & Keyword \\
\hline /i/ & heat, feed & $/ \mathrm{p} /$ & pack, happy \\
\hline /I / & sit hit & $/ b /$ & back, rubber \\
\hline 118 & & $/ \mathrm{t} /$ & tie \\
\hline /eI/ & date, paid & $/ d /$ & die \\
\hline$|\varepsilon|$ & bet, bed & $/ \mathrm{k} /$ & came, key, quick \\
\hline $\mid æ /$ & rat, bad & /g/ & game, guest \\
\hline$/ \alpha /$ & box, odd, father & $15 /$ & church, nature, watch \\
\hline 101 & bought, dog & $\mid \mathrm{d} /$ & judge, general, major \\
\hline /ov/ & boat, road & $/ f /$ & fan, photograph \\
\hline & & $\mid v /$ & van \\
\hline /ט/ & look, good & $\mid \theta /$ & thing, breath \\
\hline$/ u /$ & boot, food, student & $/ \delta /$ & then, breathe \\
\hline $\mid \Lambda /$ & but, mud, mother & $|s|$ & sip, city, psychology \\
\hline /曰/ & banana, among & $|2|$ & zip, please, goes \\
\hline 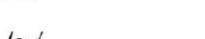 & hi- & 151 & ship, machine, station, special \\
\hline 121 & shırt, murder & $|3|$ & measure, vision \\
\hline /aI/ & bite, cry, buy, eye & $/ \mathrm{h} /$ & hot, who \\
\hline /ars/ & about, how & $/ \mathrm{m} /$ & men, some \\
\hline & & $/ \mathrm{n} /$ & sun, know, pneumonia \\
\hline /OI/ & voice, boy & / / & sung, ringing \\
\hline$| \pm r|$ & beer & $/ w /$ & wet, white \\
\hline |हr/ & bare & /l & light, long \\
\hline Jarl & & $\mid r /$ & right, wrong \\
\hline /ar/ & bar & $\mid \mathrm{y} /$ & yes, use, music \\
\hline |or/ & door & & \\
\hline /or/ & tour & & \\
\hline
\end{tabular}


APPENDIX B. SAMPLE QUESTIONS

Q3. Put the following words (in the box) under their corresponding sound symbol:

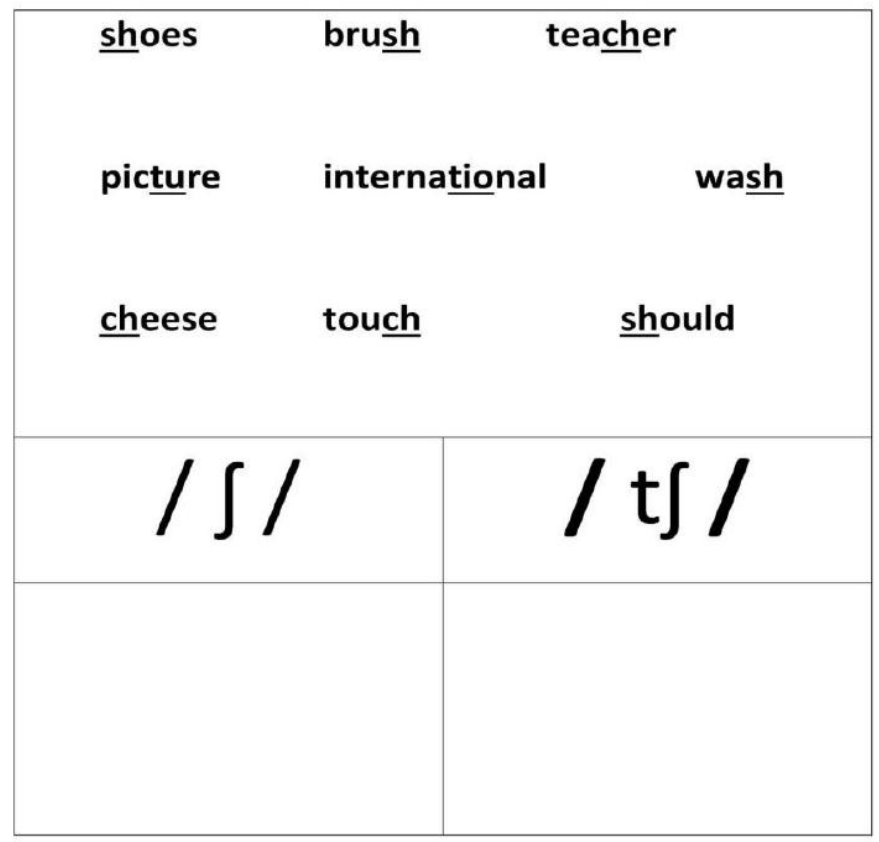

Q4. Write the words corresponding to the following phonetic codes(the first one is done for you):

\begin{tabular}{|l|l|}
\hline /ka:nt/ & can't \\
\hline / kæt/ & \\
\hline /di:p/ & \\
\hline / fa:r/ & \\
\hline /ri:d/ & \\
\hline /b3:n/ & \\
\hline /Oærak/ & \\
\hline
\end{tabular}

\section{REFERENCES}

[1] Atkielski, Anthony. (2005). Using Phonetic Transcription in Class. Retrieved October $20^{\text {th }}, 2012$ from http://www.atkielski.com/ESLPublic/Phonetics\%20-\%20Using\%20Phonetic\%20Transcription\%20in\%20Class.pdf.

[2] Blachman, Benita A. (1994). What we have learned from longitudinal studies of phonological processing and reading, and some unanswered questions. Journal of Learning Disabilities, 27, 287-291.

[3] Celce-Murcia, Marianne. (1991). Teaching English as a second or foreign language (2nd ed. ed.). Boston MA ; New York, NY: Heinle \& Heinle : Newbury House.

[4] Denes, Peter B., \& Pinson, Elliot N. (1993). The speech chain: the physics and biology of spoken language. New York, N.Y.: W.H. Freeman.

[5] Foorman, B.R. (1991). How letter-sound instruction mediates progress in first-grade reading and spelling. Journal of Educational Psychology 83, 456-469.

[6] Grabe, William. (1991). Current Developments in Second Language Reading Research. TESOL Quarterly, 25(3), 375-406.

[7] Griffith, Priscilla, and Olson, Mary W. (1992). Phonemic Awareness Helps Beginning Readers Break the Code. Reading Teacher, 45(7), 516-523.

[8] Ibrahim, Muhammad H. (1978). Patterns in Spelling Errors ELT Journal, 32(3), 207-212. 
[9] Ingvar Lundberg, Jbrgen Frost, \& Petersen, Ole-Peter. (1988). Effects of extensive program for stimulating phonological awareness in preschool children. Reading Research Quarterly, 23(3), 263-284.

[10] James Flege, \& Port, Robert. (1981). Cross-Language. Phonetic Interference: Arabic To English. Language and Speech, 24(2), 125-146.

[11] Jones, Monica L. (1996). Phonics in ESL literacy instruction: Functional or not? Paper from the proceedings of the World Conference on Literacy, Philadelphia, March 1996. (ERIC Document No. ED436104).

[12] Kenworthy, Joanne. (1987). Teaching English pronunciation. Harlow: Longman.

[13] Koren, Shira. (1995). Foreign Language Pronunciation Testing: A New Approach. System, 23(3), 387-400.

[14] Kruidenier, John. (2002). Research-based principles for adult basic education reading instruction. The National Institute for Literacy. The Partnerhsip for Reading - NIFL, National Institute of Child Health and Development, U.S. Dept. of Education, U.S. Dept. of Health and Human Services.

[15] LDCE. (2005). Longman dictionary of contemporary English (4th ed. with writing assistant. ed.). Harlow: Longman.

[16] Liu, Qian. (2011). On Current Conditions of Pronunciation Teaching and Learning under Occupation-Related Criterion. English Language and Literature Studies, Vol.1, No.2. pp.3

[17] McMullan, James. (1988). Finding Time for the Phonetic Alphabet. Modern English Teacher, 15(3), 9-12.

[18] Morley, Joan. (1994). Pronunciation, pedagogy and theory: new views, new directions. Alexandria, Va.: Teachers of English to Speakers of Other Languages.

[19] Morley, Joan. (1998). Trippingly on the tongue: Putting serious speech/pronunciation instruction back in the TESOL equation. ESL Magazine (January-February), 20-23.

[20] Pennington, Martha Carswell. (1996). English phonology in language teaching : an international approach. London: Longman.

[21] PéryWoodley, MariePaule. (1991). Writing in L1 and L2: analysing and evaluating learners' texts. Language Teaching, 24(02), 69-83.

[22] Rababah, Ghaleb. (2005). Communication problems facing Arab learners of English: A personal perspective. Journal of Language Learning 3(1), pp 180-197.

[23] Raimes, Ann. (1991). Out of the Woods: Emerging Traditions in the Teaching of Writing. TESOL Quartarly, 25(3), 406-430.

[24] Schmidt, R. (1995). Consciousness and foreign language learning: A tutorial on the role of attention and awareness in learning. In R. Schmidt (ed.). Attention and awareness in foreign language learning (pp 1-63). Honolulu: University of Hawaii Press.

[25] Stanovich, Keith E. (1993). Romance and Reality. The Reading Teacher, 47(4), 280 - 291.

[26] Stevens, Vance. (1991). Classroom Concordancing: Vocabulary Materials Derived From Relevant, Authentic Text. English for Specific Purposes, 10, 35-46.

[27] Stubbs, M. (1980). Language and literacy: The sociolinguistics of reading and writing, London: Routledge Education Books.

[28] Swan, Michael and Smith, Bernard. (2001). Learner English, Second Edition: A Teacher's Guide to Interference and other Problems. Cambridge University Press, Cambridge, UK.

[29] Richard L.Venezky. (1970). The Structure of English Orthography. The Hague: Mouton.

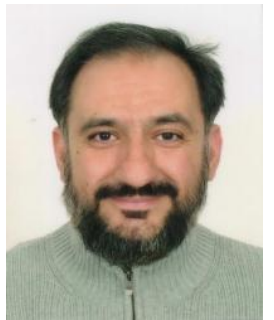

Hussam Rajab is a TESOL Doctorate (Ed.D) student at Exeter University (UK), an EFL Lecturer at Dammam Community College and Summer Program Coordinator at King Fahd University of Petroleum \& Minerals (Dhahran, Saudi Arabia). He holds two Masters, a PG Diploma, a PGCE (Leadership \& Management), a PGCE (Teaching), a TEFL Diploma (with Grammar endorsement) and TKT Essentials Teacher Training Certificate. 